\title{
Nutrition Composition of Snacks Offered to Young Recreational Soccer Players Matthew D'Aria
}

Thesis submitted to the faculty of the Virginia Polytechnic Institute and State University in partial fulfillment of the requirements for the degree of

Master of Science

In

Human Nutrition Food \& Exercise

\author{
Elena L. Serrano \\ Jay H. Williams \\ Mary M. McFerren \\ Kathy W. Hosig
}

September 25, 2015

Blacksburg, Virginia

Keywords: snacks, nutrition, youth, sports, sugar sweetened beverages, fruits, vegetables 


\title{
Nutrition Composition of Snacks Offered to Young Recreational Soccer Players
}

\author{
Matthew D'Aria
}

\begin{abstract}
Snacking behavior has changed dramatically over the past few decades, with snacking frequency reaching upwards of three times per day and comprising $27 \%$ of daily calorie intake. Research has shown that the largest food groupings from snacks are grain-based desserts, sweetened beverages, and salty snacks. Previous studies have also shown that children are influenced by their peers. Youth sports are a very popular venue for children and opportunity for physical activity, with soccer becoming one of the most popular sports among young children in the US. Youth sports, especially soccer, can be a powerful tool for promoting physical activity and healthy eating for overall health and obesity prevention. The goal of this study was to examine the nutrition composition of snacks and beverages offered to young children within a soccer league. The study utilized a cross-sectional observational study of snack foods and beverages offered to children participating in a voluntary youth soccer league in southwest Virginia. Snacks offered to children in the under-five (U5) and under-six (U6) years of age categories were observed during weekly matches using an observational checklist reflecting commonly consumed snack foods and beverages. The checklist included brand name, size of food item/beverage, and number of children (by gender) for each team observed. Undergraduate and graduate nutrition students were trained as observers to assess snacks that were offered, specifically visual item identification and portion size estimation. Food items were then classified into different food and beverage categories, including: sugar-sweetened beverages (SSBs) and $100 \%$ fruit juices; water; dairy (beverage); fruits; savory (salty) snacks; grain-based desserts; candy and dairy (food). Nutrition information was gathered for each food item and beverage and entered into a database: calories, carbohydrates, protein, fat, saturated fat, sodium, sugar, fiber, vitamin C, iron and calcium. Descriptive statistics were then computed for all nutrients by all snacks combined and by snack category across all observations. Snacks were also compared to the Smart Snacks in Schools nutrition standards. Across all teams there were a total of 687 items offered to the children: 253 beverages and 434 foods. They offered a mean of 205 calories per child. The most popular beverages were SSBs. The most popular snacks were grain-based desserts (136, 31.3\% of all snack foods), followed by fruit $(124,28.5 \%)$ and savory snacks $(117,26.9 \%)$. No vegetables were served during the observations. Snacks within the savory snack item category provided the most calories per child at 63 , followed by grain-based desserts, 58 . When offered and served with beverages, snacks offered with fruit had a more favorable nutrition profile with lower mean kilocalories, lower sodium, and lower sugars than snacks without fruit. They were also more likely to meet the Smart Snacks in School nutrition standards: 65.4\% compared to $25.6 \%$. Only $44.4 \%$ of all snack foods and beverages taken by youth players met the smart snacks standards. Categorically, $67.6 \%$ of all grain-based deserts, $100 \%$ of all candy and $100 \%$ of all dairy beverages taken by youth players did not meet the smart snacks standards. Further research is warranted to identify motivating factors for providing unhealthy snacks and
\end{abstract}


beverages to youth during sporting events. There are several limitations, including generalizability of this sample, however the study provides novel insight into snacks offered to young children during recreational soccer and can help inform future strategies and interventions to promote healthier snacks. 


\section{Acknowledgments}

I would like to first thank my mentor and advisor, Dr. Elena Serrano. Her positive attitude, confidence in me, caring nature, and constant support allowed for this project to come to completion. Elena's encouragement has given me the motivation to move forward and accomplish life goals. I would not have been able to do this without her and she should be commended for the work she does as an advisor and outside of being an advisor.

I would also like to express my humble gratitude to Dr. Jay Williams, Dr. Kathy Hosig and Dr. Mary McFerren. These committee members have been inspiring teachers and extraordinary mentors with direction, support and faith in my ability to accomplish this task. The guidance that they have provided me over this journey has been invaluable.

Additionally, I would like to thank all of my researchers who helped me collect data on the soccer fields and in the grocery store Your dedication and attention to detail is what allowed a good part of this study to come to fruition. I would also like to express my humble appreciation to the soccer league that allowed us to conduct the observations and collect data.

Last, but not least, I would like to thank my friends and family, who have supported me in all of my endeavors; I could not have done it without you. 
$\begin{array}{ll}\text { Chapter 1: Introduction } & 1\end{array}$

Chapter 2: Literature Review 2

$\begin{array}{ll}\text { Chapter 3: Manuscript } & 7\end{array}$

$\begin{array}{ll}\text { Introduction } & 7\end{array}$

$\begin{array}{ll}\text { Methods } & 8\end{array}$

$\begin{array}{ll}\text { Results } & 10\end{array}$

$\begin{array}{ll}\text { Discussion } & 13\end{array}$

$\begin{array}{ll}\text { Chapter 4: Discussion and Conclusions } & 17\end{array}$

$\begin{array}{ll}\text { References } & \mathbf{2 0}\end{array}$

$\begin{array}{ll}\text { Appendix A: Observation Check List } & 23\end{array}$ 


\section{List of Tables}

Table 1: Nutrient Composition Across Soccer Snack and Beverage Categories

Table 2: Snack Foods and Beverages With and Without Fruit

Table 3: Number and Percentage of Soccer Snack Foods and Beverages that Meet or Do Not Meet Smart Snacks in Schools Nutrition Standards

Figure 1: Amount of Snack Foods and Kcals per Snack Food Category 


\section{Chapter 1: Introduction}

Childhood obesity has been and continues to be an epidemic that plagues our children. Approximately one-third of children, more than 23 million, in the United States are overweight or obese (Ogden, Carroll, Kit, \& Flegal, 2014). The prevalence of obesity among preschool children has increased almost three-fold in the last 35 years and is currently estimated at $12.3 \%$ (Daniels, 2009). Snacking behavior has changed dramatically over the past few decades (Sebastian, Cleveland, \& Goldman, 2008), where more than $27 \%$ of daily calories are derived from snacking, with snacking frequency reaching upwards of three times per day (Piernas \& Popkin 2010). Research has shown that the largest food groupings from snacks are grain-based desserts, sweetened beverages, and salty snacks (Piernas et al., 2010). Previous studies have also shown that children are influenced by their peers (Greenhalgh et al., 2009), family (Hauser et al., 2014), and television (Sisson, Shay, Broyles, \& Leyva, 2012). Sports provide an ideal avenue to increase physical activity and move more towards an appropriate energy balance. Unfortunately, research has shown for youth baseball and youth basketball, the snacks being provided either by parents or the concession stands are unhealthy and may not be appropriate for refueling after games (Irby, Drury-Brown, \& Skelton, 2014; Thomas et al., 2012)

The goal of this study was to explore snacking behavior within a sports setting among young children. Very few studies have been conducted on this topic. 


\section{Chapter 2: Literature Review}

\section{Childhood Obesity}

Approximately one-third of children, more than 23 million in the United States, are suffering from overweight or obesity (Ogden et al., 2014). The prevalence of obesity among preschool children has increased almost three-fold in the last 35 years and is currently estimated at $12.3 \%$. Childhood obesity has been shown to have numerous physical consequences and detrimental effects on systems of the body in the short- and long-term, including increased risk of: cardiovascular disease, including hypertension and atherosclerosis; metabolic syndrome, insulin resistance, and type 2 diabetes; pulmonary concerns, such as asthma or obstructive sleep apnea; gastrointestinal conditions, such as non-alcoholic fatty liver disease and gastroesophageal reflux; and skeletal concerns, such as tibia vara or slipped capital-femoral epiphysis (Daniels, 2009). Childhood obesity is multifactorial with numerous contributors (Lobstein et al., 2015; Wang, Orleans, \& Gortmaker, 2012). Simplistically, childhood obesity occurs when there is an energy imbalance between energy consumed - what a person eats or drinks - and energy expended what the body uses for normal body functions and movement.

In regards to childhood obesity and diet, excessive calories can largely be attributed to large portion sizes, high intakes of saturated/solid fats and added sugars (often referred to as SoFAS), and frequency of eating occasions, such as snacking (Bellisle, 2014; Duffey, Steffen, Van Horn, Jacobs, \& Popkin, 2012; Reedy \& Krebs-Smith, 2010; Sebastian et al., 2008). In one

study, almost $40 \%$ of total energy (calories) consumed by children was from solid fats and added sugars, often offered as part of snacks, versus the recommendations that range from 8 to $20 \%$ of total calories (Reedy et al., 2010). Correspondingly, most US children do not consume the types and amounts of foods for a healthy lifestyle and obesity prevention. In fact, according to Hess and Slavin (2014), The National Health and Nutrition Examination Survey (NHANES) data revealed that children between the ages of two and eleven had low intakes of fiber, Vitamin D, calcium, and potassium, and are therefore considered "nutrients of concern" in the 2010 Dietary Guidelines for Americans ("Dietary Guidelines for Americans 2010” (2010)). Hess and Slavin also found that children in their study had high intakes of added sugars and refined carbohydrates. At a very early age (birth) to adolescence, a child has an innate taste preference 
for sweet and salty foods, potentially due to the fact that sweet food items typically resemble energy and salty food items resemble minerals which are necessary for the body to function (Esposito, Fisher, Mennella, Hoelscher, \& Huang, 2009). Related to energy expended, physical activity and sedentary activity are the biggest determinants for overweight and obesity. Regardless of weight status, most children's diets and activity levels can be improved.

\section{Solid Fats and Added Sugars}

The average daily intake of energy from solid fats among children (two to eighteen years old) is 433 calories (Reedy et al., 2010). The most common sources of solid fats for children are pizza and grain-based desserts. The average daily intake of calories (energy) from added sugars for children was 365 calories (Reedy et al., 2010). Sugar from sweetened beverages alone has shown to provide greater than 150 calories to an elementary school child's total energy intake for a day (Briefel, Wilson, Cabili, \& Hedley Dodd, 2013). Sugar sweetened beverages (SSBs) are beverages that have sugar or sweeteners added to them like high fructose corn syrup or corn syrup. Some of these beverages include soda, some fruit juices and sports drinks as well as other beverages (Bleich \& Wolfson, 2015; Hu \& Malik, 2010).

SSBs are also associated with consuming unhealthy snack foods (Bleich et al., 2015; Ranjit, Evans, Byrd-Williams, Evans, \& Hoelscher, 2010). In fact, when comparing children who consumed SSBs and those that did not across two different age groups (two to five years old and six to eleven years old) it was found that children who drank SSBs consumed more energy (calories) from SSBs (159 kcals and 212 kcals, respectively by age group), but also consumed more sweet and salty snacks (63 kcals and $62 \mathrm{kcals}$ ) (Bleich et al., 2015). It was estimated that if a child were to consume these levels of calories (1,420 kcals) five out of seven days in a week, then the child would gain a pound of fat every 2.5 weeks $(3,550 \mathrm{kcals})$.

\section{Snacking}

Snacking behavior in children has changed dramatically over the past few decades. According to Sebastian, Cleveland and Goldman (2008), snacking has increased in adolescents over the past 25 years and is now considered the eating occasion when the majority of calories are consumed among older youth. According to Piernas and Popkin (2010), more than 27\% of daily calories are derived from snacks, with snacking reaching upwards of three times per day. 
The largest food groupings from snacks are desserts, followed by sweetened beverages and salty snacks. Younger children (ages two to six) were found to have the highest number of snacks per day and also exhibited the largest growth in snacking in the past 30 years (1.41 more snacking events per day). More frequent snacking has been positively associated with overweight status (Nicklas, Yang, Baranowski, Zakeri, \& Berenson, 2003). Snacking behavior is largely determined by what foods and beverages are offered to children, as well as other familial influence (Hauser et al., 2014), peer influence (Greenhalgh et al., 2009), watching T.V (Sisson et al., 2012), geographic location (food deserts, food swamps) (Wang et al., 2012) and media marketing (Hingle \& Kunkel, 2012; Thomas, et al.,2012). For example, children who frequently have family meals tend to have a lower risk of becoming overweight (Hauser et al., 2014). Food marketing is very effective in influencing a child's eating behavior, including snacking (Thomas et al., 2012). Children are also positively influenced by sports figures.

\section{Physical Activity}

Regular physical activity in children is important for overall health and fitness, as well as maintaining a healthy weight. The Physical Activity Guidelines for Americans recommend that children engage in a minimum of 60 minutes of moderate-to-vigorous physical activity daily, including vigorous-intensity activity on at least three days per week ("Chapter 3: Active Children and Adolescents", 2008). Unfortunately, only one quarter of children meet these recommendations (Troiano et al., 2008). Sedentary activity is also a concern. In 2006, a multistate study found that the average family, in a cohort of 180 families varying in race and ethnicity and geographical residence (urban/suburban), had four televisions. Children across age groups ( three hours each day watching television. When combined with children who played video games and used computers, the average screen time added up to about six hours of viewing time per day (Boulos, Vikre, Oppenheimer, Chang, \& Kanarek, 2012; Jordan, Hersey, McDivitt, \& Heitzler, 2006; Jordan \& Robinson, 2008). The American Academy of Pediatrics recommends no more than two hours of screen time per day (Jordan et al., 2006; Jordan et al., 2008).

A systematic review by Ford, Ward and White (2012) examined 12 different studies related to television viewing time and diet among children ages two to six. They found that in 11 out of 12 of the studies there was a significant correlation between the length of T.V. viewing 
and eating habits. It was found that just one hour of television viewing was associated with, adverse dietary outcomes. A recent study investigated the correlation between perceived health risk from fast food consumption and television viewing. The study found that "heavy" television viewers were more inclined to believe that fast food items were less harmful to their health. The authors attribute that to "internalizing" messages that they see on television (Russell \& Buhrau, 2015). According to Hingle and Kunkel (2012), approximately 5,500 food advertisements are seen by children and adolescents each year, equating with 15.1 food advertisements per day. Of the cereals advertised to children, $66 \%$ had too much added sugars and therefore failed nutritional standards (Schwartz, Vartanian, Wharton, \& Brownell, 2008). Greater than 80\% of adolescents and greater than $95 \%$ of children viewed commercials that showcased food items high in fat, sugar or sodium; healthy food items were rarely seen (Powell, Schermbeck, Szczypka, Chaloupka, \& Braunschweig, 2011).

Team sports are a popular avenue for youth to be involved in physical activity and to also learn important life skills, such as teamwork and leadership. In 2008, over 44 million youths (approximately 66\% boys and 34\% girls) participated in youth sports throughout the US (National Council of Youth Sports, 2008). One sport that is gaining in popularity in the US is soccer. There are currently 3,055,148 youth soccer players officially registered in soccer clubs in the US; of those, 144,197 reside in Virginia (US Youth Soccer, 2015).

\section{Snacks and Sports}

Although sports can be beneficial from a physical activity perspective, they also serve as an avenue for unhealthy snacking. For example, concession stands during youth sports events often feature pizza, hot dogs, hamburgers, french fries, candy, soda, sports drinks and other items high in solid fats and added sugars (Irby et al., 2014; Thomas et al., 2012). One study observed snacking consumption of players and spectators of a youth baseball league (boys eight to eleven years old). Of the food items consumed, $89 \%$ were purchased at the concession stand and $73 \%$ were considered "less-healthy" items (french fries, potato chips, popcorn, candy, cookies, or ice cream) with ice cream, french fries, and potato chips being the most popular options. Beverage consumption of the spectators was also concerning. Over $50 \%$ of the beverages were classified as SSBs (Irby et al., 2014). In the same study, almost three-quarters of the team snacks (72\%) brought by parents were made up of unhealthy snacks, such as french fries, chips, crackers, 
candy, and cookies. There were only two items that were considered "healthier items" - granola bars and peanuts. Of the beverages brought, $32.9 \%$ of the beverages were diet sodas, $35.3 \%$ were SSBs (26.8\% sports drinks and $8.5 \%$ regular soda), and only $31.7 \%$ were water, the preferred beverage. Over half of beverages consumed in the dugout while youth players were competing, were SSBs (Irby et al., 2014). Despite the growth in popularity of youth soccer in the US, no studies to date have been published that examine snack behavior in youth soccer clubs. 


\section{Chapter 3: Manuscript}

\section{Introduction}

Snacking behavior has changed dramatically over the past few decades, particularly among youth. Children are not only snacking more frequently, but the nutrient composition of snacks is also changing. It has been estimated that children now consume upwards of three snacks per day. Increased bouts of snacking can lead to an increase in caloric intake (Bleich et al., 2015; Hu et al., 2010)(Bellisle, 2014; Duffey et al., 2012 Sebastian et al., 2008) and even excessive weight gain. Snacks have been found to comprise greater than $27 \%$ of a child's calories per day. Popular snack foods and beverages are high in solid fats and added sugars (SoFAS), such as sugar sweetened beverages (SSB's)(Reedy et al., 2010) (Hess et al., 2014) (Bleich et al., 2015; Hu et al., 2010) (Bellisle, 2014; Duffey et al., 2012 Sebastian et al.,2008), which have also been found to be associated with (unhealthy) weight status.

These changes have been observed across age groups, from toddlers to older children. Of particular interest, children between the ages of two and six were found to have the highest number of snacks per day. They also exhibited the largest growth in snacking in the past 30 years with upwards of three times per day (Piernas et al., 2010). This is a critical age period because children have been shown to have effective self-regulation of energy intake until this age, at which point they become more responsive to food cues, such as portion size. It also represents an important time to establish healthy long-term eating habits. Among older youth, snacking contributes to the majority of calories consumed (Sebastian et al., 2008). Current childhood obesity recommendations highlight the need for strategies to address snacking behavior in addition to promoting physical activity (and reducing sedentary behavior).

Although not extensively studied, youth sports offer another setting for the consumption of snack foods and beverages in addition to potentially beneficial effects of physical activity. In 2008, over 44 million youth (approximately 66\% boys and 34\% girls) participated in youth sports throughout the US (National Council of Youth Sports, 2008) of which 3.1 million comprise soccer (US Youth Soccer, 2015). Based on one study aimed at exploring the food environment of youth baseball $50 \%$ or more of the beverages consumed by players ages eight to eleven were SSBs. Almost a quarter of the snack items consumed were considered "less healthy" (Irby et al., 2014; Thomas et al., 2012). In focus groups, parents of youth basketball players ages six to thirteen recalled the most recent post-game snacks as sweets (candy, ice cream, 
doughnuts), fast food (McDonald's, Chipotle), pizza, hot dogs, tacos, and salty snacks (Thomas et al., 2012).

The goal of this study was to examine snacks foods and beverages offered to young children by parents within a voluntary youth soccer league, using a cross-sectional observational study design.

\section{Methods}

\section{Setting and Participants}

Snacks offered by parents to children within the under-five (U5) and under-six (U6) years of age categories were observed during and after weekly practices and games (Fridays from 5:00 to 6:00 pm). Each team completed 30 minutes of practice followed by a 30-minute match with an opposing team. Each team consisted of a total of six to seven players per team. All teams were members of a non-profit, recreational, voluntary, coed youth soccer league in southwest Virginia. The soccer league was endorsed by Kroger ${ }^{\mathrm{TM}}$, however no foods were provided by Kroger to the teams nor any discounts or coupons. Further, no snack policy or food education was provided to parents by the league. Practices and games took place at a site with no concession stands available. All snacks were provided by parents (not coaches or other league staff). Two teams were observed each week. Each team was selected at random.

\section{Measures}

An observational checklist reflecting commonly consumed snack foods and beverages, adapted from NEMS (med.upenn.edu 2015) and Farris' packed lunch study (Farris et al., 2015) were used to record data on the presence of all food and beverages offered during the weekly soccer matches to youth participants. The checklist included brand name, size of food item/beverage, and number of children taking firsts and seconds of each food item. Each researcher was assigned a specific team to observe. Undergraduate and graduate nutrition students were recruited and trained as researchers in direct observation to assess snack contents, specifically visual item identification and portion size estimation. The training was conducted by a member of the research team. The study was approved by the local soccer league. This study was exempt from review by the Institutional Review Board (IRB) and did not require consent, as no personal information was gathered from participants, only observational data. 


\section{Observations}

Observations were conducted during weekly matches within the same age bracket. Each match lasted approximately 30 minutes, consisting of two 15 minute halves. While collecting data for this study, only "team snacks," snacks that were brought for the whole team by a parent and were handed out post-game were recorded. Food items provided during "half time" or what parents brought specifically for their own children were excluded.

\section{Analysis}

All data captured on the observational checklist were transferred into a database. Food items were classified into five different categories: fruit; savory snacks, including cheese crackers, pretzels, chips, trail mix, popcorn; grain-based desserts, such as Moon Pies ${ }^{\mathrm{TM}}$, cookies, granola bars, graham crackers; dairy, including cheese sticks; candy, including fruit snacks. These categories were determined using a combination of food groupings from the NHANES 2003-2006 report and the 2010 Dietary Guidelines for Americans (Appliedresearch.cancer.gov., (2015); “Dietary Guidelines for Americans 2010”. (2010)). Beverage categories were SSBs and $100 \%$ Fruit Juices, Dairy and Water. 100\% fruit juice was included in the SSB category, as whole fruit is preferred to fruit juice.

The following nutrition information was gathered for each food item and beverage and entered into Microsoft Excel ${ }^{\mathrm{TM}}$ : calories, carbohydrates, protein, fat, saturated fat, sodium, sugar, fiber, vitamin C, iron and calcium (Farris et al., 2015). Nutrition information was acquired from the actual food product, the USDA nutrient database, or product webpage (in that order). Food items that were homemade or unable to be identified by brand were searched for in the USDA nutrient database. Each snack food and beverage was also compared to the Smart Snacks in School nutrition standards at the elementary level (Healthiergeneration.org,. (2015); Fns.usda.gov,. (2015)) to determine the extent to which they followed national recommendations for snacks by age and grade level. Descriptive statistics were computed for snacks, comparing snacks that contained a fruit (individually or as part of all snack options offered that day) and those that did not. Kilocalories were also computed per child for the different snacks. All statistics that were computed for mean nutrient/kcal value, the sum was taken of the nutrient/kcal in question within a specific snack or beverage category then divided by the total number of 
players observed. Each snack item category analyses were conducted with or without water, since water contains no kilocalories and nutrients.

\section{Results}

\section{Nutrient Composition of Snack Foods and Beverages}

There were a total of 687 food/beverage items: 253 beverages and 434 food items offered. Of the beverages, 232 were SSBs, including 100\% fruit juices (91.7\% of beverages), 12 bottled waters (4.7\%), and 9 dairy (3.5\%). See Table 1 and Figure 1. The most popular snack items offered were grain-based desserts (136, 31.3\% of snack food offerings), followed by fruit $(124,28.5 \%)$, savory snacks $(117,26.9 \%)$, then candy $(33,7.6 \%)$. Savory snacks provided on average 62.9 kilocalories per child (39.5\% of all calories), grain-based desserts 58.4 (36.7\%), fruit $24.8(15.6 \%)$, candy $7.3(4.5 \%)$, and dairy 5.5 (3.4\%). Correspondingly, savory snacks contained the highest mean levels of fat $(2.2 \mathrm{~g})$ followed by grain-based desserts $(1.9 \mathrm{~g})$. However, grain-based desserts contained the highest mean levels of saturated fats $(0.67 \mathrm{~g})$ followed by savory snacks $(0.46 \mathrm{~g})$. The highest mean level of sodium was $106.8 \mathrm{mg}$ in savory snacks. Grain-based desserts contained the highest mean level of sugars (excluding fruits (4.13 g) because of naturally occurring sugars) and calcium with $4.0 \mathrm{~g}$ and $20.3 \mathrm{mg}$, respectively. Beverages within the SSB category contained an average of $43.6 \mathrm{kcals}$ per child $(94.5 \%$

of kilocalories of all beverages), whereas beverages in the dairy category only 2.5 kcals per child (5.4\%) and water 0.0. They also contained the most sugar (mean), of all beverage categories, with 10.7 grams. They also contained $15.8 \mathrm{mg}$ of vitamin $\mathrm{C}$. 
Table 1. Nutrient Composition across Soccer Snack and Beverage Categories

\begin{tabular}{|c|c|c|c|c|c|c|c|c|c|c|c|c|}
\hline & $\begin{array}{l}\text { Number } \\
\text { Offered }\end{array}$ & $\begin{array}{l}\text { Mean } \\
\text { Kilocal } \\
\text { ories }\end{array}$ & $\begin{array}{c}\text { Mean } \\
\text { Fat }(\mathrm{g})\end{array}$ & $\begin{array}{c}\text { Mean } \\
\text { Saturated } \\
\text { Fat }(\mathrm{g})\end{array}$ & $\begin{array}{c}\text { Mean } \\
\text { Carbo- } \\
\text { hydrate } \\
(\mathrm{g})\end{array}$ & $\begin{array}{l}\text { Mean } \\
\text { Protein } \\
\text { (g) }\end{array}$ & $\begin{array}{l}\text { Mean } \\
\text { Sodium } \\
(\mathrm{mg})\end{array}$ & $\begin{array}{l}\text { Mean } \\
\text { Fiber } \\
(\mathrm{g})\end{array}$ & $\begin{array}{l}\text { Mean } \\
\text { Sugar } \\
(\mathrm{g})\end{array}$ & $\begin{array}{l}\text { Mean } \\
\text { Vitamin C } \\
\quad(\mathrm{mg})\end{array}$ & $\begin{array}{l}\text { Mean } \\
\text { Iron } \\
(\mathrm{mg})\end{array}$ & $\begin{array}{c}\text { Mean } \\
\text { Calcium } \\
\text { (mg) }\end{array}$ \\
\hline \multicolumn{13}{|l|}{ Food Category $(n=434)$} \\
\hline Fruits & 124 & 24.8 & 0.0 & 0.00 & 6.1 & 0.2 & 0.6 & 0.83 & 4.1 & 7.5 & 0.1 & 6.6 \\
\hline Savory Snacks & 117 & 62.9 & 2.2 & 0.46 & 9.6 & 1.3 & 106.8 & 0.50 & 1.2 & 0.09 & 0.4 & 9.8 \\
\hline Grain-Based Desserts & 136 & 58.4 & 1.9 & 0.67 & 9.4 & 0.6 & 46.2 & 0.40 & 4.0 & 0.4 & 0.4 & 20.3 \\
\hline Candy & 33 & 7.3 & 0.0 & 0.00 & 1.7 & 0.0 & 3.4 & 0.00 & 1.0 & 3.3 & 0.0 & 0.0 \\
\hline \multicolumn{13}{|l|}{ Beverage Category $(n=253)$} \\
\hline \begin{tabular}{l|l} 
Sugar Sweetened \\
Beverages
\end{tabular} & 232 & 43.6 & 0.0 & 0.00 & 11.4 & 0.0 & 19.7 & 0.06 & 10.7 & 15.8 & 0.0 & 8.1 \\
\hline Water & 12 & 0.0 & 0.0 & 0.0 & 0.0 & 0.0 & 0.0 & 0.0 & 0.0 & 0.0 & 0.0 & 0.0 \\
\hline Dairy (Beverage) & 9 & 2.5 & 0.0 & 0.0 & 0.4 & 0.1 & 2.5 & 0.0 & 0.4 & 0.0 & 0.0 & 4.7 \\
\hline
\end{tabular}

*Mean values were computed by each category's total amount for the specific nutrient divided by total number of players observed ( $\mathrm{n}=320$ ) 
Figure 1. Amount of Snack Foods and Kcals per Snack Food Category

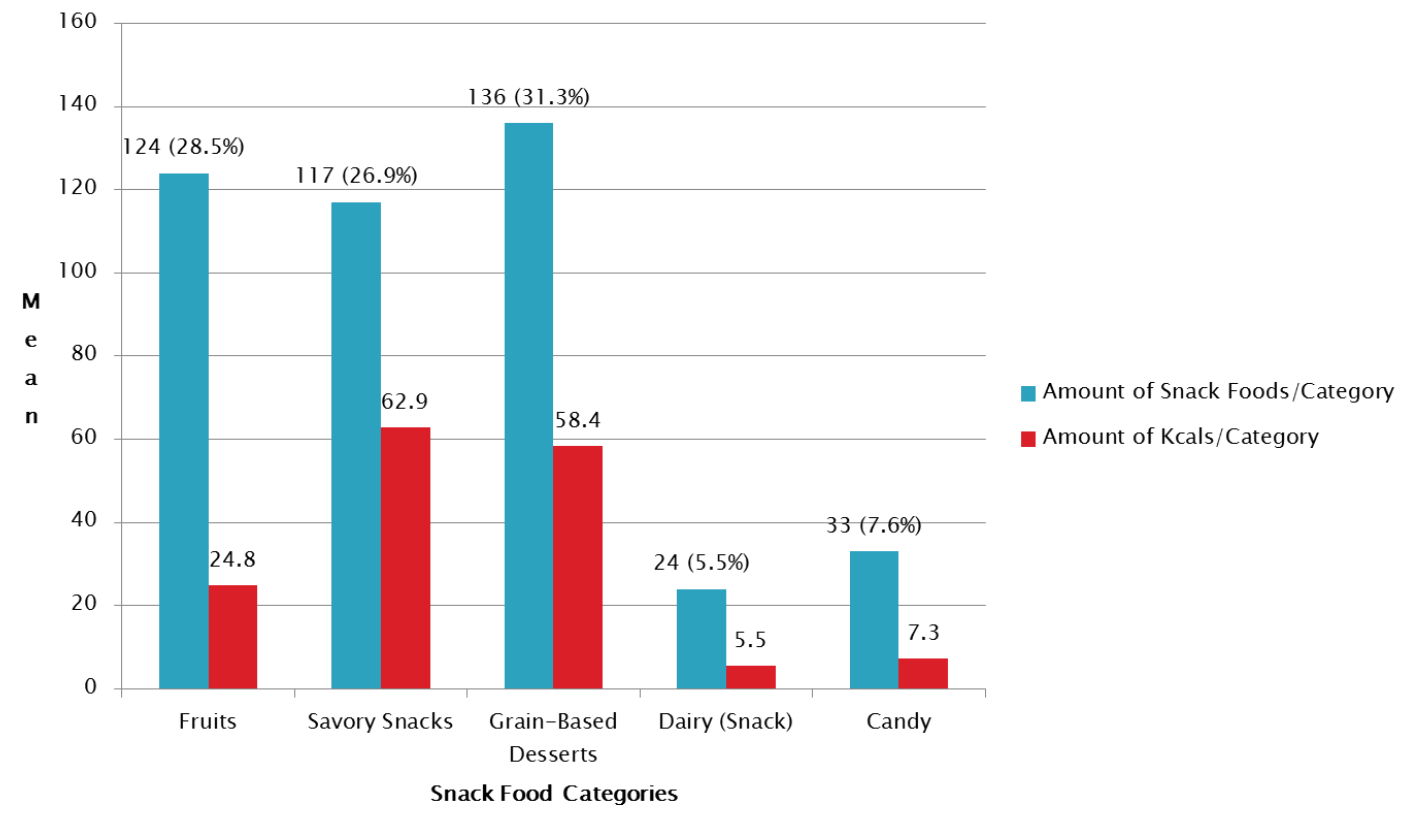

Snack Foods and Beverages Meeting Smart Snacks Standards

Overall, 44.4\% of the snack foods and beverages met the Smart Snacks in Schools standards (55.6\% did not) with a higher proportion of items containing fruit meeting the standards than those that did not. See Table 3. Based on all snack foods and beverages $(n=687)$, $30.9 \%$ of those containing fruit met the standards and $13.5 \%$ that did not. Within their respective categories, $65.4 \%$ that contained fruit met the standards compared to $25.6 \%$ that did not. Interestingly, savory snacks served with fruit were less likely to meet the standards than those not served with fruit: $61.4 \%$ versus $100.0 \%$, respectively. Snacks containing SSBs were more likely to meet the standards if served with fruit than not served with fruit: $46.6 \%$ compared to $100 \%$. "No snacks that included grain-based desserts, dairy snacks/beverages or candy also contained fruit. Further, $67.6 \%$ of grain-based desserts did not meet the standards in addition to $100 \%$ of candy and dairy beverages.

The data gathered and analyzed within this study shows that unhealthy snacks and beverages are being provided and tend to be the snacks and beverages of choice for youth soccer players when refueling after a game. These unhealthy snacks/beverages are adding unnecessary calories and potentially creating unhealthy snacking habits for refueling after an athletic event (Irby et al., 2014; Thomas et al., 2012; Schneider et al., 2011). With the data that was gathered, an educational handout could be created for the youth soccer league mentioning overall, the most popular snack items, the amount of kcals they will consume if eaten at one sitting and healthier 
alternatives. The handout could be distributed in hopes of providing awareness to the parents, coaches and league committee about the nutrition quality of snacks and beverages being provided and how positive changes can be made to benefit the youth players.

\section{Discussion and Conclusions}

This study aimed at finding the nutrition quality of snacks being provided to youth soccer players, focusing on nutrients that have been previously studied (Farris et al., 2015). The categories chosen for this study were guided by the dietary guidelines and NHANES data (“Dietary Guidelines for Americans 2010”, (2010); Appliedresearch.cancer.gov, (2015)). It found that youth players chose about the same amount of fruits, savory snacks and grain-based desserts. With increasing amounts of snacking occurring within children, a good part of their kcals are coming from snacks (Piernas et al., 2010) and this age group is a vital time in their life for creating good snacking habits that can follow them throughout their life (Marotz, L. 2014). Grain-based desserts however can be high in solid fats and added sugars (Reedy et al., 2010) and savory snacks can be high in sodium, which the data in this study shows; leading to the assumption that snacks such as grain-based desserts and savory snacks have minimal nutrient quality when compared to fresh fruits. Sugar sweetened beverages and $100 \%$ juice beverages dominated the youth player's beverage choice by making up $92 \%$ of the beverages chosen. It is interesting to find these beverages being brought by parents because the children were expected to bring a water bottle and water is the recommended beverage of choice for sports at this age level (Schneider \& Benjamin, 2011). With the amount of grain-based desserts, savory snacks SSB's and $100 \%$ fruit juices offered to youth players, it suggests that the level of knowledge for proper rehydration and refueling for children at this age level is low; warranting an education intervention directed towards the parents providing team snacks within this league. However, more research is needed for a better understanding of the actual level of knowledge of the parents and the reasons behind their choices of bringing these specific team snacks/beverages.

In this study specific nutrients were observed: fats, saturated fats, carbohydrates, protein, sodium, fiber, sugar, vitamin C, iron and calcium. These nutrients were captured for each snack and beverage category and then compared to the Dietary Reference Intakes for the four to eight years age group. Grain-based desserts showed the highest amount (when compared to all snack 
categories) of mean solid fats and sugars which is not uncommon for these types of snack foods (Reedy et al., 2010).

\section{Limitations}

There were limitations to this study that need to be noted. Only one youth soccer league was observed in rural setting in Southwest Virginia. Youth soccer leagues within highly populated areas or urban settings may have different snack compositions than rural settings. There were only 2 age categories that were focused on during this study limiting the amount of participants and getting a broader view of the snack and beverage composition for other age categories. Since most children if not all did not finish their snacks and beverages on the field the researchers had to assume the child ate the whole snack which may or may not have occurred. Food items were given out during half time as well as at the end of the game. This could have affected a players' decisions to take or not take snack items at the end of the game. No statistical tests could be computed since group-level data.

\section{Implications}

Snack composition at youth sports can be a way to observe how snacks are affecting youth that play sports. Other studies should be conducted focusing on energy expenditure for youth soccer players; parents perceptions of healthy and unhealthy snacks and beverages for refueling within youth soccer players; conducting focus groups on why parents bring the snacks they do; comparing youth soccer leagues within rural and urban settings; comparing the health literacy levels of parents and the snacks being provided to youth soccer players; and the efficacy of an intervention on educating parents about providing healthy snacks to see if educating parents is enough to make healthy snack choices. These results warrant educational campaigns targeting parents of youth playing rec sports and league policies regarding snacks provided. 
Table 2. Snack Foods and Beverages With and Without Fruit

\begin{tabular}{|c|c|c|c|c|c|c|c|c|c|c|c|c|}
\hline & $\begin{array}{l}\text { Number } \\
\text { offered }\end{array}$ & $\begin{array}{c}\text { Mean } \\
\text { kilocalories }\end{array}$ & $\begin{array}{l}\text { Mean } \\
\text { Fat }(g)\end{array}$ & $\begin{array}{c}\text { Mean } \\
\text { Saturated } \\
\text { Fat }(\mathrm{g})\end{array}$ & $\begin{array}{l}\text { Mean } \\
\text { Carbo- } \\
\text { hydrate } \\
(\mathrm{g})\end{array}$ & $\begin{array}{l}\text { Mean } \\
\text { Protein } \\
(\mathrm{g})\end{array}$ & $\begin{array}{l}\text { Mean } \\
\text { Sodium } \\
(\mathrm{mg})\end{array}$ & $\begin{array}{l}\text { Mean } \\
\text { Fiber } \\
(\mathrm{mg})\end{array}$ & $\begin{array}{c}\text { Mean } \\
\text { Sugar }(g)\end{array}$ & $\begin{array}{l}\text { Mean } \\
\text { Vitamin } \\
\text { C (mg) }\end{array}$ & $\begin{array}{l}\text { Mean } \\
\text { Iron } \\
(\mathrm{mg})\end{array}$ & $\begin{array}{l}\text { Mean } \\
\text { Calcium } \\
(\mathrm{mg})\end{array}$ \\
\hline $\begin{array}{l}\text { Snack Foods and } \\
\text { Beverages offered } \\
\text { with Fruit }\end{array}$ & 298 & 72.4 & 1.4 & 0.4 & 17.0 & 0.8 & 50.9 & 0.8 & 9.4 & 12.2 & 0.3 & 24.5 \\
\hline $\begin{array}{l}\text { Snack Foods } \\
\text { offered with Fruit } \\
\text { Not Including } \\
\text { Beverages }\end{array}$ & 48 & 15.7 & 0.1 & 0.0 & 3.5 & 0.2 & 19.7 & 0.2 & 1.4 & 2.1 & 0.1 & 1.5 \\
\hline $\begin{array}{l}\text { Snack Foods and } \\
\text { Beverages offered } \\
\text { without Fruit }\end{array}$ & 346 & 119.6 & 3.1 & 0.8 & 22.0 & 1.6 & 118.3 & 0.8 & 11.7 & 12.6 & 0.6 & 33.4 \\
\hline $\begin{array}{l}\text { Snack Foods } \\
\text { offered without } \\
\text { Fruit Not Including } \\
\text { Beverages }\end{array}$ & 19 & 7.2 & 0.1 & 0.1 & 1.0 & 0.1 & 11.7 & 0.0 & 0.4 & 0.0 & 0.0 & 2.2 \\
\hline
\end{tabular}

* Mean values were computed by each category's total amount for the specific nutrient divided by total number of players observed ( $\mathrm{n}=320)$. 
Table 3. Number and Percentage of Soccer Snack Foods and Beverages that Meet or Do Not Meet Smart Snacks in Schools Nutrition Standards

\begin{tabular}{|c|c|c|c|c|c|c|c|c|c|}
\hline & Fruit & Savory Snacks & $\begin{array}{l}\text { Grain- } \\
\text { Based } \\
\text { Desserts }\end{array}$ & $\begin{array}{l}\text { Dairy } \\
\text { (snack) }\end{array}$ & Candy & $\begin{array}{c}\text { Sugar- } \\
\text { Sweetened } \\
\text { Beverages }\end{array}$ & Water & $\begin{array}{c}\text { Dairy } \\
\text { (Beverage) }\end{array}$ & Total \\
\hline $\begin{array}{l}\text { Snack Foods and } \\
\text { Beverages Containing Fruit }\end{array}$ & 124 & 11 & 0 & 0 & 0 & 189 & 0 & 0 & 324 \\
\hline $\begin{array}{l}\text { Meets Smart } \\
\text { Snacks Standards }\end{array}$ & $124(100.0)$ & 0 & 0 & 0 & 0 & $88(46.6)$ & 0 & 0 & $212(65.4)$ \\
\hline \begin{tabular}{|l|} 
Does Not Meet \\
Smart Snack \\
Standards
\end{tabular} & 0 & $11(100.0)$ & 0 & 0 & 0 & $101(53.4)$ & 0 & 0 & $112(34.6)$ \\
\hline $\begin{array}{l}\text { Snack Foods and } \\
\text { Beverages without Fruit }\end{array}$ & 0 & 106 & 136 & 24 & 33 & 43 & 12 & 9 & 363 \\
\hline $\begin{array}{l}\text { Meets Smart } \\
\text { Snacks Standards }\end{array}$ & 0 & $13(12.3)$ & $44(32.4)$ & $24(100.0)$ & 0 & 0 & $12(100.0)$ & 0 & $93(25.6)$ \\
\hline $\begin{array}{l}\text { Does Not Meet } \\
\text { Smart Snacks } \\
\text { Standards }\end{array}$ & 0 & $93(87.7)$ & $92(67.6)$ & 0 & $33(100.0)$ & $43(100.0)$ & 0 & 9 & $270(74.4)$ \\
\hline
\end{tabular}

*Food items were deemed either meeting or not meeting Smart Snacks in School standards by answering and inputting data about the snacks nutrient content into an online program called the "Alliance Product Calculator."

Percentages are computed based on the number of items that do or do not meet the Smart Snacks in Schools standards by food category and by containing fruit or not. 


\section{Chapter 4: Discussions and Conclusions}

Fiber is one of the nutrients deemed a nutrient of concern for children aged 2-11 through the current (2010) dietary guidelines (Dietary Guidelines for Americans 2010). The data analyzed in this study found that fruits provided $0.83 \mathrm{~g}$ (3.3\% Adequate Intake) for 4-8 year olds of mean fiber, while savory snacks and grain-based desserts offered half or less, of the amount of mean fiber, $0.50 \mathrm{~g}$ (2.0\% AI for 4-8 year olds) and 0.40 (1.6\% AI for 4-8 year olds). This shows that even though grain-based desserts and savory snacks within this study provided fiber, fruits provided more fiber as an individual snack group and could have offered a significant amount more of fiber if they were the only snack item represented for the total amount of snacks, bringing the youth players closer to the recommended amount of fiber/day. Interestingly, the fruit items individually had higher fiber, but when combined with other snack food items had lower fiber/child. Calcium is another nutrient noted as a nutrient of concern for children aged 211. We found that of all snack and beverage categories, grain-based desserts provided the highest mean calcium (20.3 mg (2.0\% of the Recommended Daily Allowance (RDA)) followed by savory snacks (9.8 $\mathrm{mg}(0.9 \% \mathrm{RDA})$ and SSBs $(8.1 \mathrm{mg}(0.81 \%$ RDA). The data suggests both for fiber and calcium that parents may offset their positive choices (e.g. fruit) with unhealthy choices (e.g. savory snacks, grain-based desserts and SSBs). More research is warranted to better understand snack choices within this setting.

Similar outcomes were found for other nutrients with unhealthy snacks and beverages providing a majority of the nutrients when including all snack and beverage categories. The highest intake of mean carbohydrates came from SSBs (11.4 g (8.8\% (RDA)) followed by savory snacks $(9.6 \mathrm{~g}(7.3 \% \mathrm{RDA}))$ and grain-based desserts $(9.4 \mathrm{~g}(7.2 \%))$ where fruits only provided $6.1 \mathrm{~g}(4.73 \% \mathrm{RDA}))$. The highest intake of mean protein derived from savory snacks $(1.31 \mathrm{~g}$ (8.9\% RDA)) followed by grain-based desserts (0.63 g (3.32\% RDA)) and then dairy (snacks) $(0.35 \mathrm{~g}(1.85 \% \mathrm{RDA}))$. The highest intake of mean sodium was from savory snacks (106.8 $\mathrm{mg}$ (8.9\% AI)) followed by grain-based desserts (46.2 g (3.8\% AI)) and then SSBs (19.7 (1.64\% $\mathrm{AI})$ ). The highest consumption of mean vitamin C came from SSBs (15.8 mg (63.1\% (RDA)) followed by fruits (7.5 mg (30.1\% (RDA)) and then candy (13.0\% (RDA)). Amount of mean sugar provided, were highest in SSBs (10.7 g) followed by fruits (3.14 g), grain-based desserts $(4.01 \mathrm{~g})$ and then savory snacks $(1.15 \mathrm{~g})$. It is alarming to see that the highest amount of each mean nutrient came from an unhealthy snack or beverage. These findings warrant further 
research in why these snack items and beverages tend to be the offering of choice after a youth soccer game.

\section{Comparison to Other Sports Snacks Data}

Not many studies have been conducted on the nutrient quality of snacks being provided to youth athletes, so it was difficult to compare the results to other studies; however, the results from this study were similar to the other snacking in sports studies. Low nutrient quality snacks tended to dominate the snacks being consumed as well as SSB's and 100\% fruit juices being the top choice in beverages of youth players (Irby et al., 2014, Thomas et al., 2010). With the choices of overall snack quality in youth sports being low (Irby et al., 2014, Thomas et al., 2010), it is of great concern that snacks being provided at youth sports could be potentially introducing unhealthy snacking habits (Irby et al., 2014). This is interesting because youth sports promote exercise which is part of having a healthy lifestyle. Countless articles have mentioned that in order to have a healthy lifestyle, one must exercise and have proper nutrition. This is an issue considering the current research done on snacks provided at youth sports as well as this study. The snacks being provided do not seem to promote healthy eating habits for the youth players (Irby et al., 2014, Thomas et al., 2010).

\section{Conclusion}

Snacking plays a significant role in a child's dietary intake for the day. Snacks may counteract beneficial effects of physical activity. According to this study as well as others, snacks and beverages being provided to youth athletes tend to be unhealthy and provide unnecessary calories. It is evident that more research needs to be conducted to find out the reasons behind unhealthy snacks being offered.

\section{Implications}

Snack composition at youth sports can be a way to observe how snacks are affecting youth that play sports. Other studies should be conducted focusing on energy expenditure for youth soccer players; parents perceptions of healthy and unhealthy snacks and beverages for refueling within youth soccer players; conducting focus groups on why parents bring the snacks they do; comparing youth soccer leagues within rural and urban settings; comparing the health literacy levels of parents and the snacks being provided to youth soccer players; and the efficacy 
of an intervention on educating parents about providing healthy snacks to see if educating parents is enough to make healthy snack choices. These results warrant educational campaigns targeting parents of youth playing rec sports and league policies regarding snacks provided. 


\section{References}

1. Ogden, C. L., Carroll, M. D., Kit, B. K., \& Flegal, K. M. (2014). Prevalence of childhood and adult obesity in the United States, 2011-2012. JAMA, 311(8), 806-814. doi: 10.1001/jama.2014.732

2. Daniels, S. R. (2009). Complications of obesity in children and adolescents. Int J Obes (Lond), 33 Suppl 1, S60-65. doi: 10.1038/ijo.2009.20

3. Sebastian, R. S., Cleveland, L. E., \& Goldman, J. D. (2008). Effect of snacking frequency on adolescents' dietary intakes and meeting national recommendations. J Adolesc Health, 42(5), 503-511. doi: 10.1016/j.jadohealth.2007.10.002

4. Piernas, C., \& Popkin, B. M. (2010). Trends in snacking among U.S. children. Health Aff (Millwood), 29(3), 398-404. doi: 10.1377/hlthaff.2009.0666

5. Greenhalgh, J., Dowey, A. J., Horne, P. J., Fergus Lowe, C., Griffiths, J. H., \& Whitaker, C. J. (2009). Positive- and negative peer modelling effects on young children's consumption of novel blue foods. Appetite, 52(3), 646-653. doi: 10.1016/j.appet.2009.02.016

6. Hauser, S. I., Economos, C. D., Nelson, M. E., Goldberg, J. P., Hyatt, R. R., Naumova, E. N., . . Must, A. (2014). Household and family factors related to weight status in first through third graders: a cross-sectional study in Eastern Massachusetts. BMC Pediatr, 14, 167. doi: 10.1186/1471-2431-14-167

7. Sisson, S. B., Shay, C. M., Broyles, S. T., \& Leyva, M. (2012). Television-viewing time and dietary quality among U.S. children and adults. Am J Prev Med, 43(2), 196200. doi: 10.1016/j.amepre.2012.04.016

8. Irby, M. B., Drury-Brown, M., \& Skelton, J. A. (2014). The food environment of youth baseball. Child Obes, 10(3), 260-265. doi: 10.1089/chi.2013.0161

9. Thomas, M., Nelson, T. F., Harwood, E., \& Neumark-Sztainer, D. (2012). Exploring parent perceptions of the food environment in youth sport. J Nutr Educ Behav, 44(4), 365-371. doi: 10.1016/j.jneb.2011.11.005

10. Lobstein, T., Jackson-Leach, R., Moodie, M., Hall, K., Gortmaker, S., \& Swinburn, B. et al. (2015). Child and adolescent obesity: part of a bigger picture. The Lancet, 385(9986), 2510-2520. http://dx.doi.org/10.1016/s0140-6736(14)61746-3

11. Wang, Y. C., Orleans, C. T., \& Gortmaker, S. L. (2012). Reaching the healthy people goals for reducing childhood obesity: closing the energy gap. Am J Prev Med, 42(5), 437-444. doi: 10.1016/j.amepre.2012.01.018

12. Bellisle, F. (2014). Meals and snacking, diet quality and energy balance. Physiol Behav, 134, 38-43. doi: 10.1016/j.physbeh.2014.03.010

13. Duffey, K. J., Steffen, L. M., Van Horn, L., Jacobs, D. R., Jr., \& Popkin, B. M. (2012). Dietary patterns matter: diet beverages and cardiometabolic risks in the longitudinal Coronary Artery Risk Development in Young Adults (CARDIA) Study. Am J Clin Nutr, 95(4), 909-915. doi: 10.3945/ajcn.111.026682

14. Reedy, J., \& Krebs-Smith, S. M. (2010). Dietary sources of energy, solid fats, and added sugars among children and adolescents in the United States. J Am Diet Assoc, 110(10), 1477-1484. doi: 10.1016/j.jada.2010.07.010

15. Hess, J., \& Slavin, J. (2014). Snacking for a cause: nutritional insufficiencies and excesses of U.S. children, a critical review of food consumption patterns and macronutrient and micronutrient intake of U.S. children. Nutrients, 6(11), 47504759. doi: 10.3390/nu6114750 
16. USDA and HHS. (2010). Retrieved 11 January 2014, from

http://www.cnpp.usda.gov/sites/default/files/dietary_guidelines_for_americans/Po licyDoc.pdf

17. Esposito, L., Fisher, J. O., Mennella, J. A., Hoelscher, D. M., \& Huang, T. T. (2009).

Developmental perspectives on nutrition and obesity from gestation to adolescence. Prev Chronic Dis, 6(3), A94.

18. Briefel, R. R., Wilson, A., Cabili, C., \& Hedley Dodd, A. (2013). Reducing calories and added sugars by improving children's beverage choices. J Acad Nutr Diet, 113(2), 269-275. doi: 10.1016/j.jand.2012.10.016

19. Bleich, S. N., \& Wolfson, J. A. (2015). U.S. adults and child snacking patterns among sugar-sweetened beverage drinkers and non-drinkers. Prev Med, 72, 8-14. doi: 10.1016/j.ypmed.2015.01.003

20. Hu, F. B., \& Malik, V. S. (2010). Sugar-sweetened beverages and risk of obesity and type 2 diabetes: epidemiologic evidence. Physiol Behav, 100(1), 47-54. doi: 10.1016/j.physbeh.2010.01.036

21. Ranjit, N., Evans, M. H., Byrd-Williams, C., Evans, A. E., \& Hoelscher, D. M. (2010). Dietary and activity correlates of sugar-sweetened beverage consumption among adolescents. Pediatrics, 126(4), e754-761. doi: 10.1542/peds.2010-1229

22. Nicklas, T. A., Yang, S. J., Baranowski, T., Zakeri, I., \& Berenson, G. (2003). Eating patterns and obesity in children. The Bogalusa Heart Study. Am J Prev Med, 25(1), 9-16.

23. Sisson, S. B., Shay, C. M., Broyles, S. T., \& Leyva, M. (2012). Television-viewing time and dietary quality among U.S. children and adults. Am J Prev Med, 43(2), 196200. doi: 10.1016/j.amepre.2012.04.016

24. Hingle, M., \& Kunkel, D. (2012). Childhood obesity and the media. Pediatr Clin North $A m, 59(3), 677-692$, ix. doi: 10.1016/j.pcl.2012.03.021

25. US Department of Health and Human Services, Office of Disease Prevention and Health Promotion, Office of the Assistant Secretary for Health, Physical Activity Guidelines for Americans. Retrieved June 3, 2015, from http://www.health.gov/paguidelines/guidelines/chapter3.aspx

26. Troiano, R. P., Berrigan, D., Dodd, K. W., Masse, L. C., Tilert, T., \& McDowell, M. (2008). Physical activity in the United States measured by accelerometer. Med Sci Sports Exerc, 40(1), 181-188. doi: 10.1249/mss.0b013e31815a51b3

27. Boulos, R., Vikre, E. K., Oppenheimer, S., Chang, H., \& Kanarek, R. B. (2012). ObesiTV: how television is influencing the obesity epidemic. Physiol Behav, 107(1), 146-153. doi: 10.1016/j.physbeh.2012.05.022

28. Jordan, A. B., Hersey, J. C., McDivitt, J. A., \& Heitzler, C. D. (2006). Reducing children's television-viewing time: a qualitative study of parents and their children. Pediatrics, 118(5), e1303-1310. doi: 10.1542/peds.2006-0732

29. Jordan, A. B., \& Robinson, T. N. (2008). Children, Television Viewing, and Weight Status: Summary and Recommendations from an Expert Panel Meeting. The ANNALS of the American Academy of Political and Social Science, 615(1), 119132. doi: $10.1177 / 0002716207308681$

30. Ford, C., Ward, D., \& White, M. (2012). Television viewing associated with adverse dietary outcomes in children ages 2-6. Obes Rev, 13(12), 1139-1147. doi: 10.1111/j.1467-789X.2012.01028.x 
31. Russell, C. A., \& Buhrau, D. (2015). The role of television viewing and direct experience in predicting adolescents' beliefs about the health risks of fast-food consumption. Appetite, 92, 200-206. doi: 10.1016/j.appet.2015.05.023

32. Schwartz, M. B., Vartanian, L. R., Wharton, C. M., \& Brownell, K. D. (2008). Examining the nutritional quality of breakfast cereals marketed to children. J Am Diet Assoc, 108(4), 702-705. doi: 10.1016/j.jada.2008.01.003

33. Powell, L. M., Schermbeck, R. M., Szczypka, G., Chaloupka, F. J., \& Braunschweig, C. L. (2011). Trends in the nutritional content of television food advertisements seen by children in the United States: analyses by age, food categories, and companies. Arch Pediatr Adolesc Med, 165(12), 1078-1086. doi:

10.1001/archpediatrics.2011.131

34. National Council of Youth Sports. Report on Trends and Participation In Organized Youth Sports. (2008). Retrieved June 3, 2015, from http://www.ncys.org/pdfs/2008/2008-ncys-market-research-report.pdf

35. United States Youth Soccer, Number of Youth Soccer Players. (n.d.). Retrieved January 3, 2015, from http: www.usyouthsoccer.org

36. Glanz, K., Sallis, J., Saelens, B., \& Frank, L. (2007). Nutrition Environment Measures Survey in Stores (NEMS-S)Development and Evaluation. American Journal of Preventive Medicine, 32(4), 282-289. http://dx.doi.org/10.1016/j.amepre.2006.12.019

37. Farris, A. R., Misyak, S., Duffey, K. J., Mann, G. R., Davis, G. C., Hosig, K., . . Serrano, E. L. (2015). A comparison of fruits, vegetables, sugar-sweetened beverages, and desserts in the packed lunches of elementary school children. Child Obes, 11(3), 275-280. doi: 10.1089/chi.2014.0134

38. Marotz, L. (2014). Health, safety, and nutrition for the young child. (9th ed., p. 437). Wadsworth Publishing.

39. Schneider, M., \& Benjamin, H. (2011). Sports Drinks and Energy Drinks for Children and Adolescents--Are They Appropriate?: A Summary of the Clinical Report. American Academy Of Pediatrics, 127(6), 1182-1189.

40. National Cancer Institute. (2015). Table 1. Mean intake \& major sources of energy, solid fats \& added sugars among children \& adolescents in the United States (218 years old). Retrieved 17 September 2015, from http://appliedresearch.cancer.gov/diet/foodsources/article/table1.html\#f_b

41. USDA Food and Nutrition Service (2015). Tools for Schools: Focusing on Smart Snacks Food and Nutrition Service. Retrieved 23 January 2015, from

http://www.fns.usda.gov/healthierschoolday/tools-schools-focusing-smart-snacks

42. American Heart Association \& Clinton Foundation. (2015). Alliance Product Calculator. Retrieved 17 September 2015, from https://www.healthiergeneration.org/take_action/schools/snacks_and_beverages/s mart_snacks/alliance_product_calculator/ 


\section{Appendix A: Observational Checklist}

Number on Team:

Team Color:
Soccer Division: U5/U6

Number of Male:

Number of Female:
Date:

Recorder:

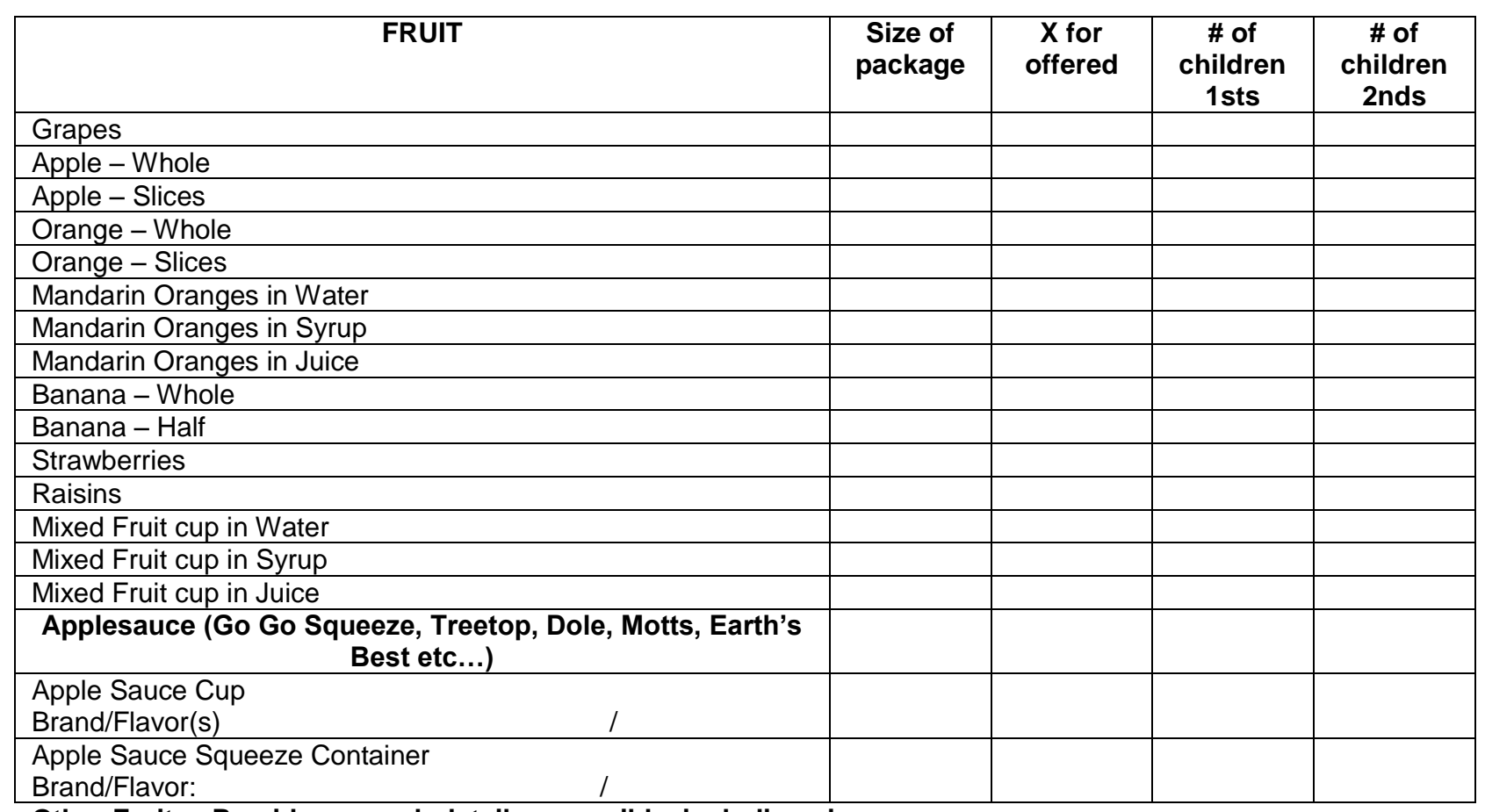

Other Fruits. Provide as much detail as possible, including size.

\begin{tabular}{|l|l|l|l|l|}
\hline \multicolumn{1}{|c|}{ SAVORY SNACKS } & $\begin{array}{c}\text { Size of } \\
\text { package }\end{array}$ & $\begin{array}{c}\text { X for } \\
\text { offered }\end{array}$ & $\begin{array}{c}\text { \# of } \\
\text { children } \\
\text { 1sts }\end{array}$ & $\begin{array}{c}\text { \# of } \\
\text { children } \\
\text { 2nds }\end{array}$ \\
\hline Chips, Brand/Flavor: & & & & \\
\hline Pretzels (pkg). List brand: & & & & \\
\hline Goldfish (pkg). List brand: & & & & \\
\hline Cheez-its (pkg). List brand/Flavor: & & & & \\
\hline $\begin{array}{l}\text { Cheese Stick/String Cheese, Brand and Flavor: } \\
\text { / }\end{array}$ & & & & \\
\hline Bagels. Brand/Flavor: & & & & \\
\hline Nutri-Grain Bar. Flavor & & & & \\
\hline Energy Bar. Brand/Flavor & & & \\
\hline Crackers \& Cheese Dip (pkg) & & & \\
\hline $\begin{array}{l}\text { Popcorn (pkg). List brand: } \\
\text { List type (i.e. Sea salt, popped, etc.): }\end{array}$ & & & & \\
\hline $\begin{array}{l}\text { Trail Mix (M \& Ms, nuts, raisins). List brand: } \\
\text { or list contents as specifically as possible: }\end{array}$ & & & & \\
\hline Yogurt - Brand/Flavor: & & & & \\
\hline
\end{tabular}


Other Savory Snacks. Provide as much detail as possible, including the brand, type, and size.

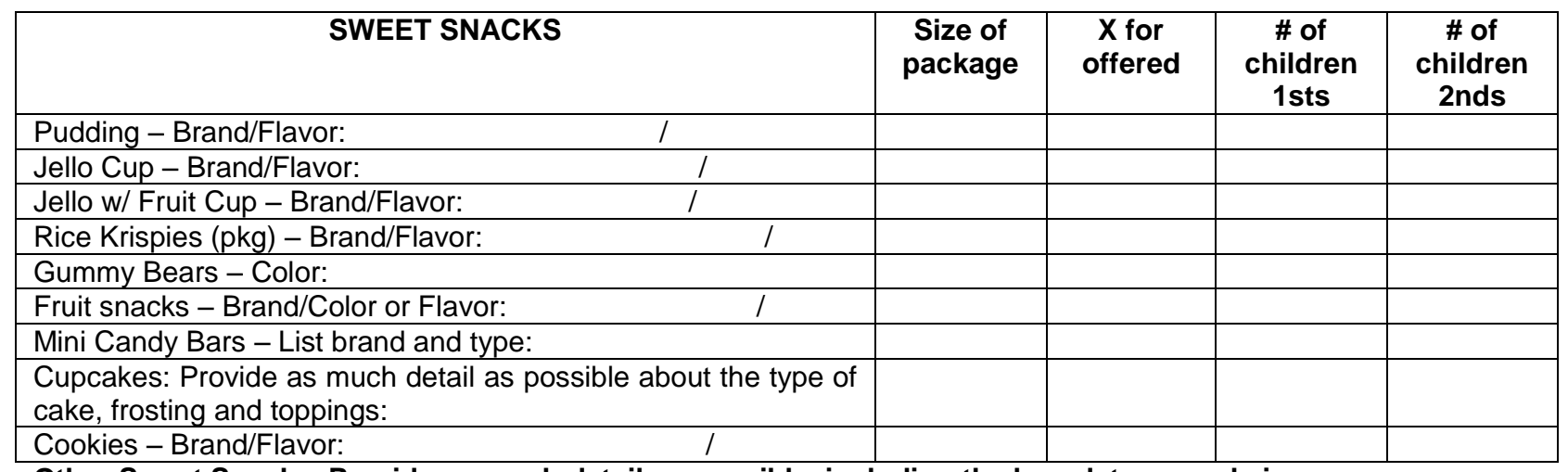

Other Sweet Snacks. Provide as much detail as possible, including the brand, type, and size.

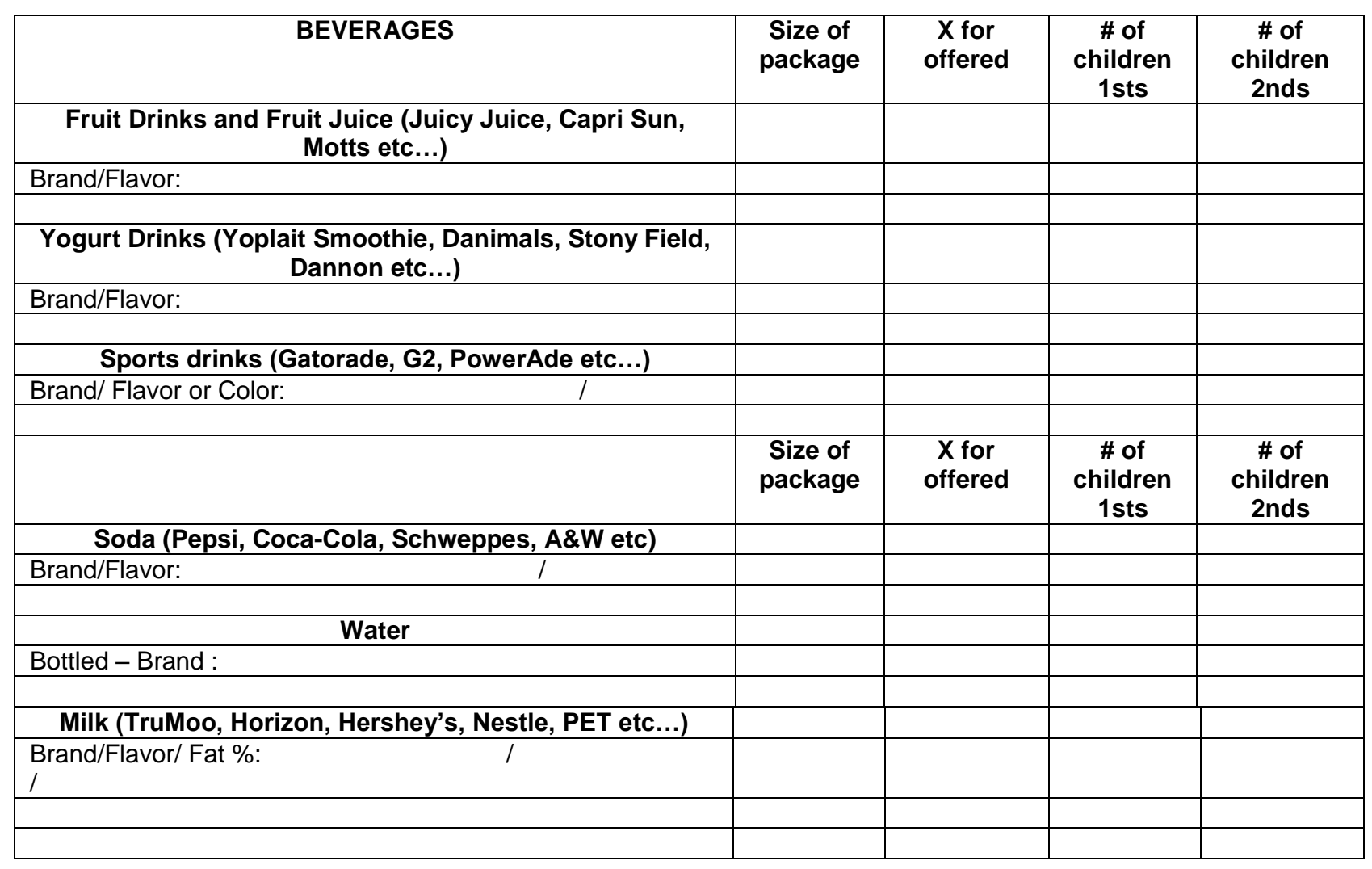

Other Beverages. Provide as much detail as possible, including the brand, type, and size. 